\title{
Intermediate- to long-term outcomes of transvaginal mesh for treatment of Asian women with pelvic organ prolapse
}

\author{
Symphorosa SC Chan *, Osanna YK Wan, KW Choy, Rachel YK Cheung
}

\section{A B S T R A C T}

Introduction: Short-term follow-up analyses suggest that transvaginal mesh has limited application for pelvic organ prolapse (POP) treatment. This study evaluated the intermediateand long-term outcomes of transvaginal mesh surgery.

Methods: This retrospective study included all women who underwent transvaginal mesh surgery in one urogynaecology centre. Inclusion criteria were women with stage III/IV POP, age $\geq 65$ years, and (preferably) sexual inactivity. Concomitant sacrospinous fixation and mid-urethral slings were offered for stage III/IV apical POP and urodynamic stress incontinence, respectively. Women were followed up for 5 years. Subjective recurrence was defined as reported prolapse symptoms. Objective recurrence was defined as stage II prolapse or above. Mesh complications and patient satisfaction were reviewed.

Results: Of 183 women who underwent transvaginal mesh surgery, 156 had $\geq 1$ year of follow-up (mean, $50 \pm 22$ months). Subjective and objective recurrence rates were $5.1 \%$ and $10.9 \%$, respectively. The mesh erosion rate was $9.6 \%$; all affected women received

This article was published on $17 \mathrm{Dec}$ 2021 at www.hkmj.org. local oestrogen treatment or bedside surgical excision. Three women received transobturator tension-free transvaginal tape for de novo $(n=1)$ or preoperative urodynamic stress incontinence who did not undergo concomitant surgery $(n=2)$; $14 \%$ of the women had de novo urgency urinary incontinence. No women reported chronic pain. Overall, 98\% were 'satisfied' or 'very satisfied' with the operation.

Conclusion: During 50 months of follow-up, transvaginal mesh surgery for stage III/IV POP had low subjective and objective recurrence rates. The total re-operation rate was $9.6 \%$. Most women were satisfied with the operation. Based on the riskbenefit profile, transvaginal mesh surgery may be suitable for women who have advanced POP.

\section{Hong Kong Med J 2021;27:413-20 \\ https://doi.org/10.12809/hkmj208714}

SSC Chan *, MD, FRCOG

OYK Wan, FHKAM (Obstetrics and Gynaecology), FHKCOG

KW Choy, MSc (Med), PhD

RYK Cheung, FRCOG, FHKAM (Obstetrics and Gynaecology)

Department of Obstetrics and Gynaecology, The Chinese University of Hong Kong, Hong Kong

*Corresponding author: symphorosa@cuhk.edu.hk

New knowledge added by this study

- In women with stage III or IV pelvic organ prolapse, transvaginal mesh surgery (with concomitant sacrospinous fixation for stage III or IV apical compartment prolapse) had low subjective (5.1\%) and objective (10.9\%) rates of recurrence, along with a high satisfaction rate (98\%), during approximately 50 months of follow-up.

- In sexually inactive women, the transvaginal mesh erosion rate is low.

- Although some women required re-operations because of factors such as pelvic organ prolapse recurrence, stress urinary incontinence, and mesh erosion, the overall re-operation rate was $9.6 \%$.

Implications for clinical practice or policy

- In contrast to previous recommendations, transvaginal mesh surgery may be suitable for women who are sexually inactive, particularly women who have a higher risk of prolapse recurrence related to conditions such as advanced pelvic organ prolapse and levator ani muscle avulsion.

\section{Introduction}

Pelvic organ prolapse (POP) leads to considerable symptomatic distress and reduced quality of life among women. ${ }^{1,2}$ Large-scale studies of women in the United States and Europe have shown that the risks of undergoing POP or stress urinary incontinence (SUI) surgery by 80 years of age range from $12.6 \%$ to $18.7 \%{ }^{3-5}$ Advanced POP stage and worse quality of life are factors that increase the likelihood of surgical treatment. ${ }^{2}$ Symptom resolution is the most important goal among women who seek consultations for POP. ${ }^{6}$ Importantly, quality of life improves in women who undergo surgical treatment. ${ }^{7}$ However, there is a high mean recurrence rate after 


\section{經陰道網片修補術對患盆底器官脫垂之亞洲婦女 的中期到長期報告 \\ 陳丞智、温綺琪、蔡偉光、張優嘉}

引言：短期隨訪分析顯示經陰道網片修補術對治療盆底器官脱垂的應 用有限。本研究評估經陰道網片修補術的中期和長期結果

方法：這項回顧性研究納入在一所泌尿婦科中心接受經陰道網片修補 術的所有婦女。納入標準為患有第三或第四程度盆底器官脱垂、年齡 65 歲或以上和性生活不活躍的婦女。為第三及四程度陰道中路脱垂和 經尿動力學證明壓力性尿失禁患者分別提供骶棘固定和無張力性人工 陰道帶手術。隨訪期為5年。主觀復發定義為脱垂症狀。客觀復發定 義為第二程度或以上脱垂。檢視術後併發症和患者滿意度。

結果：在接受經陰道網片修補術的183名婦女中，156名的隨訪時間 1 年或以上（平均50士22個月）。主觀和客觀復發率分別為 $5.1 \%$ 和 $10.9 \%$ 。網片侵蝕率為 $9.6 \%$; 所有受影響婦女都接受局部雌激素 治療或床邊手術切除。3名婦女因新發 $(n=1)$ 或術前經尿動力學證 明壓力性尿失禁接受無張力性人工陰道帶手術, 但未接受伴隨手術 （n=2）；14\%婦女患有新發急迫性尿失禁。沒有慢性疼痛報告。總 體而言，98\%對手術感到「滿意」或「非常滿意」。

結論：在50個月的隨訪期間, 經陰道網片修補術對第三或第四程度盆 底器官脱垂的主觀和客觀復發率較低。總再手術率為 $9.6 \%$ 。大部份患 者對手術感到滿意。根據風險收益情況, 經陰道網片修補術可能適合 患有晚期盆底器官脱垂的婦女。
POP surgery: $36 \%$ after a follow-up interval of 0.1 to 10 years. Reoperation is also common (29.2\%) and the between-procedure interval decreases with successive repairs. ${ }^{3,8}$

A systematic review and meta-analysis of 25 randomised controlled trials revealed that, compared with native tissue repair, transvaginal mesh surgery for anterior compartment prolapse has reduced risks of awareness of prolapse (risk ratio $=0.66,95 \%$ confidence interval $=0.54-0.81$ ), recurrent prolapse (risk ratio $=0.4,95 \%$ confidence interval $=0.3-0.53$ ), and repeat surgery for prolapse (risk ratio $=0.53,95 \%$ confidence interval $=0.31-0.88$ ) over 1 to 3 years of follow-up. ${ }^{9}$ However, transvaginal mesh surgery carried an increased risk of repeat surgery for a composite outcome of prolapse, SUI, and mesh erosion (risk ratio $=2.4,95 \%$ confidence interval=1.51-3.81). Considering this risk-benefit profile, the authors concluded that transvaginal mesh has limited utility in primary surgery; however, the quality of analysed evidence only ranged from very low to moderate. Among the randomised controlled trials considered in that systematic review, only one was conducted in Asia. Moreover, high objective and subjective cure rates of transvaginal mesh and a low mesh erosion rate have been reported over 5 to 7 years of follow-up, although some studies have had a high rate of loss to follow-up..$^{10-12}$
The present study was performed to evaluate the long-term outcome of transvaginal mesh surgery for advanced anterior compartment prolapse in a tertiary centre. It also investigated the recurrence rate and the types of postoperative complications among women who underwent transvaginal mesh surgery.

\section{Methods}

\section{Patients}

This was a retrospective analysis of prospectively collected data concerning transvaginal mesh reconstructive surgeries performed for POP treatment from January 2008 to June 2019 in a urogynaecology training centre. Ethics approval was obtained (CREC 2015.125); the ethics committee waived the requirement for informed consent. All women who underwent transvaginal mesh surgery in the study centre were recruited. Demographic data, including age, parity, mode of delivery, urinary symptoms (eg, SUI and/or urgency urinary incontinence [UUI]), and symptoms of prolapse were collected during the first consultation; the Pelvic Organ Prolapse Quantification assessment was also performed. ${ }^{13}$ Management options of vaginal ring pessary and surgery were offered. For women who chose surgery, a urodynamic study was arranged.

Transvaginal mesh surgery (ie, anterior vaginal mesh or total vaginal mesh) was available to women with stage III or IV anterior and apical and posterior compartment prolapse, age $\geq 65$ years, and (preferably) sexual inactivity, or with recurrent POP. Beginning in January 2013, vaginal mesh insertion in the posterior compartment was not performed because of published evidence indicating no improvement from posterior vaginal mesh, compared with native tissue repair alone. ${ }^{14}$ Transvaginal mesh was performed with concomitant vaginal hysterectomy or a uterine-preserving operation depending on each woman's choice and medical condition. In women with stage III or IV apical compartment prolapse, concomitant bilateral sacrospinous fixation was performed. Because of variations in commercial product availability, Prolift $^{\circledR}$, Perigee ${ }^{\circledR}$, and Restorelle ${ }^{\circledR}$ were used from 2008 to 2012, 2013 to August 2017, and September 2017 to June 2019, respectively.

\section{Surgical procedure}

Women were admitted on the day of the operation. One dose of prophylactic intravenous antibiotics was administered on induction. The operation was performed under either spinal or general anaesthesia depending on each woman's choice and the attending anaesthetist's assessment. For women who chose hysterectomy, the operation began with vaginal hysterectomy, followed by hydrodissection 
with adrenaline solution and midline incision over the anterior vaginal wall. Subsequent dissection of the bladder from the anterior vaginal wall was performed; the sacrospinous ligament was reached without opening the posterior vaginal wall. Sacrospinous ligament fixation was conducted using a Mayo-hook from 2008 to 2017; it was conducted using a Capio device ${ }^{\circledR}$ from 2018 to 2019. Depending on the mesh design, anterior mesh was introduced and all arms either passed through the obturator membranes (Prolift ${ }^{\circledR}$ and Perigee ${ }^{\circledR}$ ) or were fixed to the ipsilateral pelvic wall and sacrospinous ligament using stitches (Restorelle ${ }^{\circledR}$ ). Anterior mesh was then attached to the bladder fascia and anterior vaginal wall using absorbable stitches. If total vaginal mesh was performed, the posterior vaginal wall was opened at the midline and the sacrospinous ligament was identified; the arms of posterior mesh were introduced to the sacrospinous ligaments. Cystoscopy was performed to exclude bladder injury and confirm ureteric jets. Per rectal examination was performed to exclude rectal perforation. Only the edge of the vaginal epithelium was trimmed; the anterior vaginal wall was closed by three interrupted stitches at the distal region, followed by continuous sutures. In the event of symptomatic posterior compartment prolapse, posterior colporrhaphy was performed. Concomitant continence surgery (ie, mid-urethral sling) was performed for women with urodynamic stress incontinence (USI). At the end of the operation, one piece of vaginal gauze soaked with chlorhexidine solution was packed into the vagina and a transurethral Foley catheter was placed. Most vaginal hysterectomies were performed by gynaecology trainees; all procedures involving mesh were performed by urogynaecologists or urogynaecology subspecialty trainees under direct supervision by urogynaecologists. Operative details including anaesthesia type, operative time, blood loss, and any organ injuries were collected from electronic operative notes that were completed by surgeons immediately after the operation.

\section{Postoperative care and follow-up}

Oral intake was resumed on the day of the operation. Standard oral paracetamol were administered. One course of antibiotics was administered to women with a high risk of infection (eg, patients with diabetes mellitus and/or a prolonged operation) and women with postoperative fever that persisted for more than 24 hours. The vaginal gauze and Foley catheter were removed on the day after the operation. Women were discharged from day 1 onwards if they resumed a normal diet, voided well, and remained afebrile.

Women were followed up once at 2 to 4 months, then annually until 5 years after surgery. Subsequently, if they had no active pelvic floor symptoms, they were discharged from the clinic.
Earlier follow-up was offered on request. During follow-up examinations, the attending gynaecologist specifically asked women about symptoms of prolapse, SUI, UUI, vaginal bleeding, pain, and dyspareunia, as well as the severity of such symptoms. Vaginal examinations were performed to assess any recurrence of prolapse or mesh erosion, in accordance with recommendations of the International Urogynecological Association and International Continence Society. ${ }^{15,16}$ Satisfaction (ie, very unsatisfied, unsatisfied, satisfied, or very satisfied) was recorded during each postoperative visit. Subjective recurrence was defined as reported symptoms of prolapse, vaginal bulge, or dragging sensation. Objective recurrence was defined by the Pelvic Organ Prolapse Quantification assessment with any compartment reaching $\geq 1 \mathrm{~cm}$ above the hymen (stage $\geq \mathrm{II}$ ). In the event of mesh erosion, the location, size, and area of mesh erosion were recorded. Vaginal oestrogen cream was offered. The options of conservative management or surgical excision of exposed mesh were discussed with women who experienced mesh erosion, depending on the erosion severity, accompanying symptoms, and their personal preferences.

If women reported symptoms of SUI or UUI, a urodynamic study was offered. If USI was diagnosed, tension-free vaginal tape surgery was offered to women for whom pelvic floor exercises were ineffective. Medical treatment was offered to women with overactive bladder or detrusor overactivity.

\section{Statistical analysis}

SPSS software (Windows version 21.0; IBM Corp, Armonk [NY], United States) was used to analyse the collected data. Categorical data are shown using descriptive statistics. Normally distributed data are shown as means (standard deviations), whereas non-normally distributed data are shown as medians (ranges). The times to subjective and objective recurrences were depicted using KaplanMeier curves. A P value of $<0.05$ was considered statistically significant.

\section{Results}

\section{Demographic characteristics, operative data, and postoperative outcomes among all patients}

In total, 183 women (mean age, $71.8 \pm 8.4$ years) underwent transvaginal mesh surgery. Nearly all were Hong Kong Chinese women, with the exception of two who were non-Chinese Asian women. The characteristics of the overall cohort are shown in the Table.

The operative procedures and hospital stay are summarised in the Table. Forty-six (25.1\%) women had spinal anaesthesia. The mean operative time 
TABLE. Characteristics of the overall cohort and the women with $\geq \mathrm{I}$ year of follow-up*

\begin{tabular}{|c|c|c|}
\hline & $\begin{array}{l}\text { Overall cohort } \\
\qquad(n=183)\end{array}$ & $\begin{array}{c}\text { Women with } \geq 1 \\
\text { year of follow- } \\
\text { up }(n=156)\end{array}$ \\
\hline Age, y & $71.8 \pm 8.4$ & $71.6 \pm 8.8$ \\
\hline Vaginal parity & $3.6 \pm 1.9$ & $3.7 \pm 1.9$ \\
\hline Sexually inactive & $178(97.3 \%)$ & $137(87.8 \%)$ \\
\hline History of pelvic floor repair surgery & $36(19.7 \%)$ & $30(19.2 \%)$ \\
\hline History of hysterectomy & $48(26.2 \%)^{\dagger}$ & $40(25.6 \%)$ \\
\hline History of continence surgery & $9(4.9 \%)$ & $8(5.1 \%)$ \\
\hline \multicolumn{3}{|l|}{ Overall staging } \\
\hline Stage II & $9(4.9 \%)$ & $9(5.8 \%)$ \\
\hline Stage III/IV & $174(95.1 \%)$ & $147(94.2 \%)$ \\
\hline \multicolumn{3}{|l|}{ Anterior compartment } \\
\hline Stage II & $15(8.2 \%)$ & $15(9.6 \%)$ \\
\hline Stage III/IV & $168(91.8 \%)$ & $141(90.4 \%)$ \\
\hline \multicolumn{3}{|l|}{ Apical compartment } \\
\hline Stage II & $58(31.7 \%)$ & $38(24.4 \%)$ \\
\hline Stage III/IV & $125(68.3 \%)$ & $106(67.9 \%)$ \\
\hline \multicolumn{3}{|l|}{ Posterior compartment } \\
\hline Stage I/II & $133(72.7 \%)$ & $100(64.1 \%)$ \\
\hline Stage III/IV & $50(27.3 \%)$ & $42(26.9 \%)$ \\
\hline Preoperative SUI & $104(56.8 \%)$ & $88(56.4 \%)$ \\
\hline Preoperative UUI & $93(50.8 \%)$ & $77(49.4 \%)$ \\
\hline Preoperative voiding difficulty ${ }^{\ddagger}$ & $80(43.7 \%)$ & $69(44.2 \%)$ \\
\hline \multicolumn{3}{|l|}{$\begin{array}{l}\text { Preoperative urodynamic study diagnosis } \\
(\mathrm{n}=179)^{\S}\end{array}$} \\
\hline USI & $58(32.4 \%)$ & $53(34.0 \%)$ \\
\hline Detrusor overactivity & $12(6.7 \%)$ & $11(7.1 \%)$ \\
\hline USI + detrusor overactivity & $9(5.0 \%)$ & $8(5.1 \%)$ \\
\hline Normal findings & $100(55.9 \%)$ & $84(53.8 \%)$ \\
\hline \multicolumn{3}{|l|}{ Operative procedures } \\
\hline Anterior vaginal mesh & $137(74.9 \%)$ & $110(70.5 \%)$ \\
\hline Both anterior and posterior vaginal mesh & $46(25.1 \%)$ & $46(29.5 \%)$ \\
\hline Vaginal hysterectomy & $110(60.1 \%)$ & $93(59.6 \%)$ \\
\hline Sacrospinous fixation & $91(49.7 \%)$ & $67(42.9 \%)$ \\
\hline Posterior pelvic floor repair & $46(25.1 \%)$ & $42(26.9 \%)$ \\
\hline TVT-O & $52(28.4 \%)$ & $46(29.5 \%)$ \\
\hline Hospital stay, d, median (range) & $2.0(2.0-4.0)$ & $2.0(2.0-4.0)$ \\
\hline Follow-up period, mo & $44 \pm 26$ & $50 \pm 22$ \\
\hline
\end{tabular}

Abbreviations: POP = pelvic organ prolapse; SUI = stress urinary incontinence;TVT-O = tension-free transvaginal tape (transobturator route); USI = urodynamic stress incontinence; UUI = urgency urinary incontinence

Data are presented as No. (\%) or mean \pm standard deviation

Of these 48 women, 29 had concomitant POP surgery

Examples: manual reduction required during voiding, a slow stream, or a sense of incomplete emptying

$\S$ Four women did not undergo a urodynamic study before the operation was $122.9 \pm 40.7$ minutes and the mean blood loss was $193 \pm 155 \mathrm{~mL}$. Three (1.6\%) women required blood transfusion. One woman had bladder injury during the trocar insertion of the anterior vaginal mesh; the involved trocar was immediately removed and reinserted in the correct surgical plane. Cystoscopy showed a small perforation site at the lateral bladder wall, but no repair was required. The woman recovered uneventfully. One woman had a mesh infection with abscess formation in the vulva, requiring removal of the anterior mesh on day 18 . The infection subsided with antibiotics and drainage, but the woman died 7 weeks after surgery because of other medical morbidities. ${ }^{17}$

Overall, one woman was lost to follow-up and three women, including the woman mentioned above, died of medical diseases within 1 year; thus, $179(97.8 \%)$ women were eligible for the postoperative outcome analysis. Of these 179 women, 23 (12.8\%) underwent operation within 1 year prior to this report, while 156 (87\%), 113 (63\%), and 77 (43\%) had completed 1,3 , and 5 years of follow-up, respectively. The mean duration of follow-up was $50 \pm 22$ months. There were no differences in demographics, preoperative symptoms, stage and compartment of prolapse, or operative data between the 23 women with $<1$ year of follow-up and the 156 women with $\geq 1$ year of follow-up, except for the vaginal mesh brand (because of variations in commercial product availability) and the duration of follow-up (Table).

\section{Postoperative outcomes among women with $\geq 1$ year of follow-up}

Among the 156 women with $\geq 1$ year of follow-up, eight reported symptoms of prolapse recurrence (subjective recurrence rate of 5.1\%). Five women had stage II POP, while three women had stage III POP. Four women experienced recurrence in the first year of follow-up; two, one, and one additional women experienced recurrence in the second, third, and fourth year of follow-up, respectively. While five women with recurrence had conservative treatment for POP, one woman had vaginal pessary and two $(1.3 \%)$ women had surgery to manage prolapse recurrence. In addition, nine other women had asymptomatic stage II POP: two had anterior compartment prolapse and seven had posterior compartment prolapse. The objective recurrence rate was $10.9 \%(n=17)$. The mesh erosion rate was $9.6 \%$ $(n=15)$. In all, $40 \%$ of the erosions $(n=6)$ occurred at the posterior wall; the remaining erosions occurred at other sites in the vagina (four anterior wall, four vaginal vault, and one lateral wall). Most instances of mesh erosion $(n=8,53.3 \%)$ occurred in the first year. Ten of the 15 affected women underwent surgical excision under local anaesthesia at the bedside; seven, one, and two women required one, two, and three surgical excisions, respectively. The times to 
subjective and objective recurrences are depicted using Kaplan-Meier curves (Fig 1).

The preoperative and postoperative symptoms of SUI are listed in Figure 2. Occult USI was observed in $11(16.2 \%)$ of 68 women who reported no SUI before the operation. Among four women who had occult USI and did not undergo continence surgery, two had postoperative SUI; they did not require surgical treatment. De novo SUI occurred in 12 (7.7\%) women. Only one (1/53, $1.9 \%)$ woman received tension-free transvaginal tape (transobturator route) [TVT-O] for treatment of SUI; the remaining 11 women had mild symptoms or achieved improvement with pelvic floor exercise. Among the 31 women who had preoperative SUI but normal urodynamic study findings and did not undergo continence surgery, 19 (61.2\%) women had postoperative SUI. Among them, two received TVT-O afterwards. Overall, 22 (14\%) women had de novo UUI: seven received anticholinergics and the remaining 15 had conservative treatment. No women reported vaginal pain, pelvic pain, or dyspareunia.

In summary, the total re-operation rate was 9.6\%: two women for recurrent POP, 10 women for mesh erosion, three women for TVT-O, and one woman for de novo SUI. In all, 103 (66\%) women and $50(32.1 \%)$ women were 'satisfied' and 'very satisfied', respectively, with the operation at their latest follow-up examination. Three women who ever had recurrence did not report being 'satisfied' or 'very satisfied'.

\section{Discussion}

This study provided a comprehensive evaluation of the intermediate- to long-term (ie, 3 to 5 years) outcomes of transvaginal mesh surgery in women with advanced POP. Risk factors for POP recurrence reportedly include levator ani muscle avulsion (odds ratio $=2.8$ ), preoperative stage III-IV POP (odds ratio $=2.1$ ), family history (odds ratio $=1.8$ ), and large hiatal area (odds ratio $=1.06$ per $\left.1 \mathrm{~cm}^{2}\right){ }^{8}$ The prevalence of levator ani muscle avulsion is higher in women with more advanced POP: we previously reported that $54.5 \%$ and $66.7 \%$ of women with stage III and IV POP had levator ani muscle avulsion, respectively. ${ }^{18}$ Although this factor was not evaluated in the present study, we presume that a similar proportion of our cohort would have this condition, placing them at high risk of POP recurrence. Indeed, transvaginal mesh repair leads to a lower rate of anterior compartment prolapse recurrence, compared with native tissue repair in women with levator ani muscle avulsion. ${ }^{19,20}$

Transvaginal mesh was not recommended in a systematic review and meta-analysis of 25 randomised controlled trials, based on its riskbenefit profile. The risk of awareness of prolapse was $13 \%$; the risks of repeat surgery for prolapse and

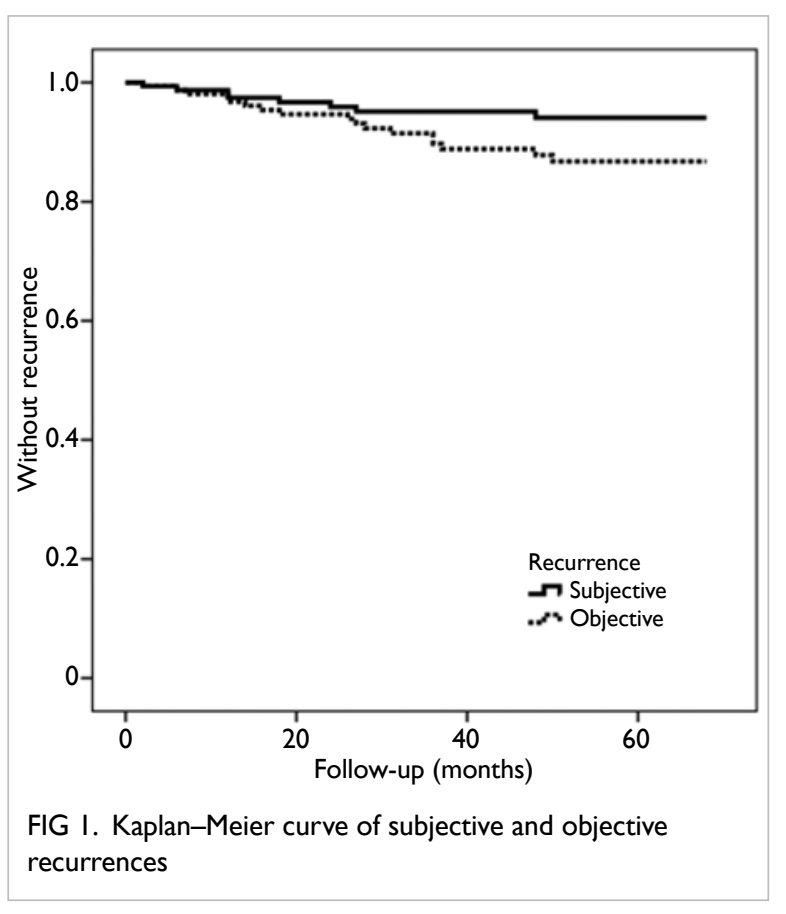

SUI were $1.8 \%$ and $2.9 \%$, respectively. ${ }^{9}$ However, if the transvaginal mesh treatment efficacy remains high over a longer follow-up period and the risk of morbidity is low, the above recommendation may not apply to all women. In our cohort, these risks were $5.1 \%, 1.3 \%$, and $1.9 \%$ for a mean follow-up period of 50 months. This indicates a tendency towards lower POP recurrence risks in our cohort. The objective recurrence rate of $10.6 \%$ also tended to be lower, compared with previous studies that recruited women who had stage II $\mathrm{POP}^{8}$, although $95 \%$ of our women had stage III or IV POP. Our subjective and objective recurrence rates are similar to the rates in other Asian centres in the past decade. ${ }^{10,11}$

Apical compartment prolapse is more prevalent among women in Hong Kong, compared with Caucasian women. ${ }^{18,21}$ Furthermore, apical support is important in the management of anterior compartment prolapse, which comprises impairment of the pubovisceral muscle and the uterosacral and cardinal ligaments. ${ }^{10,22,23}$ Thus, we performed concomitant sacrospinous fixation to suspend the vaginal vault among women in this study; this additional procedure did not increase perioperative morbidity. This may explain why the vaginal vault was not commonly involved in women who had subjective or objective recurrence of POP in the present study. Most women with objective recurrence had stage II posterior compartment prolapse, but they were asymptomatic.

The mesh erosion rate was 9.6\%; $40 \%$ of erosions were caused by posterior vaginal mesh. The erosion rate for anterior vaginal mesh alone 

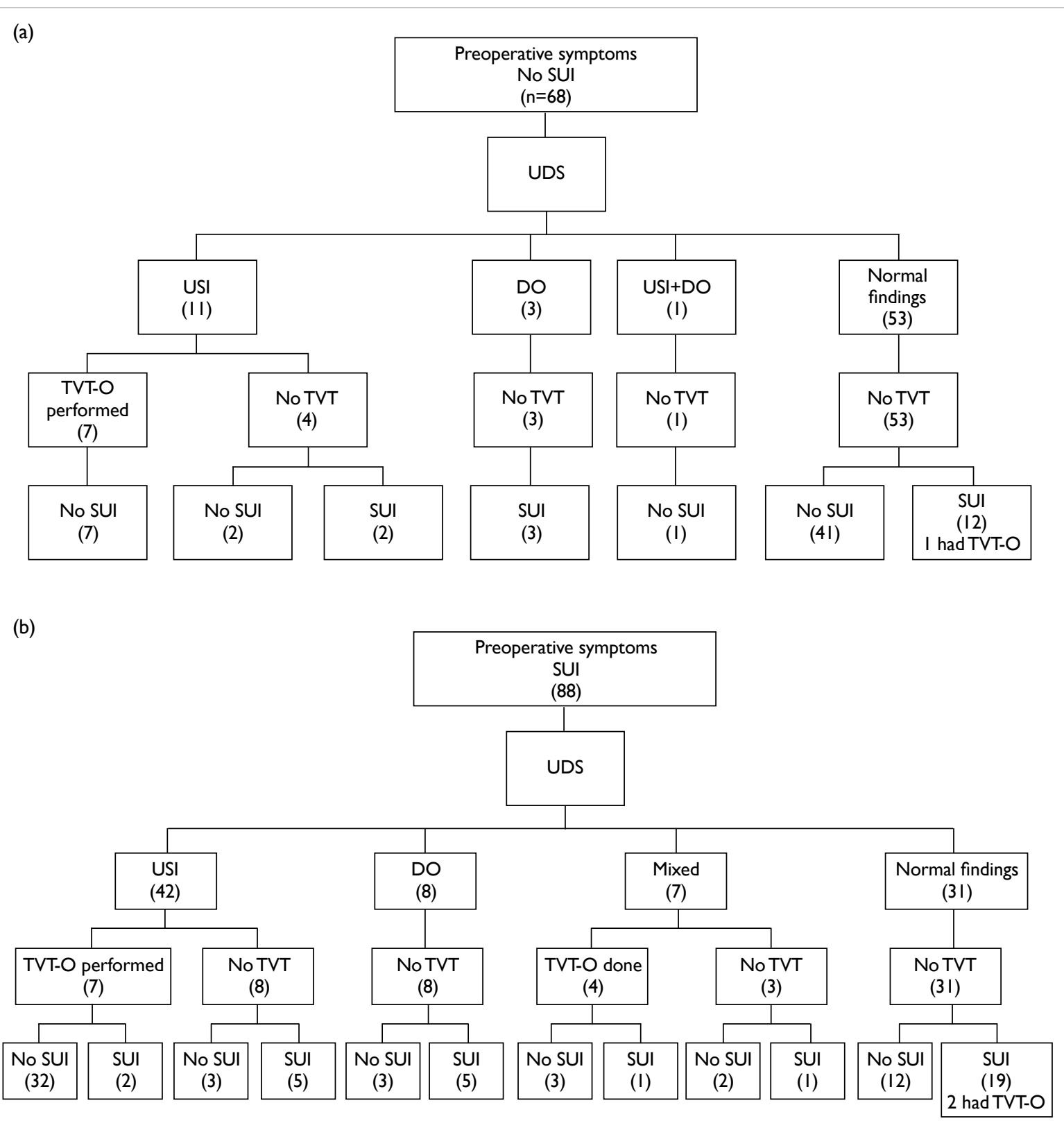

FIG 2. Preoperative and postoperative SUI symptoms and preoperative urodynamic study results. (a) Women who reported SUI before the operation; (b) Women who did not report SUI before the operation

Abbreviations: DO = detrusor overactivity; SUI = stress urinary incontinence;TVT = tension-free vaginal tape;TVT-O = tension-free vaginal tape (transobturator route); UDS = urodynamic studies; USI = urodynamic stress incontinence

was 5.8\%; this was comparable with previously was the most common complication that required reported rates of $2.7 \%$ to $20 \%$, with a mean of re-operation; however, it was also treated most 11.1\%. ${ }^{10,11,24-26}$ Furthermore, our rate was similar to effectively. However, more serious complications other Asian centres where a low mesh erosion rate could occur, such as erosion into the urinary tract or was reported. ${ }^{10,11}$ Most instances of erosion in our bowel. ${ }^{24}$ No instances of vaginal pain or dyspareunia study occurred within the first or second year of were reported in our cohort, in contrast to previous follow-up; approximately two-thirds of the affected findings ${ }^{26}$; this was presumably because we mainly women underwent excision of the exposed part offered transvaginal mesh surgery to women who of the mesh and repair of the vaginal epithelium were sexually inactive. The proportion of women under local anaesthesia at the bedside. ${ }^{17}$ Among with POP who report sexual inactivity is generally the various types of possible mesh complications, high (64\%) in Hong Kong. ${ }^{27}$ Further research is Warembourg et $\mathrm{al}^{24}$ reported that mesh erosion needed to determine whether ethnicity contributes 
to vaginal pain or dyspareunia after transvaginal mesh surgery.

Preoperative urodynamic studies showed that, of 68 women who did not report SUI, $16 \%$ and $6 \%$ had occult USI and other diagnoses, respectively; thus, only $53(78 \%)$ women had no abnormal findings. De novo SUI occurred in 12 of these 53 women (7.7\% of all 156 women with $\geq 1$ year of follow-up); only one woman requested continence surgery. Although some women reported symptoms of SUI, our policy was not to offer continence surgery if no USI was evident during the urodynamic study. Of the remaining 31 of 53 women with no abnormal findings, only two subsequently required continence surgery. Overall, repeat surgery for SUI only occurred in three (1.9\%) women; we regarded this as a low risk of repeat surgery. Preoperative urodynamic studies and our more conservative approach (ie, not frequently offering continence surgery) might have reduced the risk of long-term complications. However, treatment was offered to women with preoperative clinically bothersome USI. Women who received concomitant TVT-O were satisfied with this management.

This study had some limitations. First, this was a single-centre study with a moderate sample size. However, the data were collected prospectively using a standardised form. Second, a health-related quality of life questionnaire was not used because validated questionnaires were unavailable when transvaginal mesh surgery first began in our centre; thus, no data were available for some women. ${ }^{1} \mathrm{We}$ plan to investigate these data in a future study. Finally, the effects of sexual function on the surgical outcomes were not explored because most women in this cohort were sexually inactive. We did not recommend transvaginal mesh surgery to women who were sexually active because there were increased risks of mesh erosion and dyspareunia.

\section{Conclusion}

Women with stage III or IV POP experienced a benefit from transvaginal anterior mesh surgery (and concomitant sacrospinous fixation if concomitant stage III/IV apical compartment prolapse) with low risks of subjective recurrence of POP (5.1\%), objective recurrence of POP (10.9\%), and reoperation for POP recurrence $(1.3 \%)$ at a mean follow-up interval of 50 months. Although some women required re-operations because of various factors (eg, POP recurrence, SUI, and mesh erosion), the overall re-operation rate was 9.6\%. Most women were satisfied or highly satisfied with the transvaginal mesh surgery. This type of surgery may be suitable for women with POP who are sexually inactive, particularly women who have a higher risk of recurrence related to conditions such as advanced POP and levator ani muscle avulsion.

\section{Author contributions}

Concept or design: All authors.

Acquisition of data: SSC Chan, OYK Wan, RYK Chung.

Analysis or interpretation of data: All authors.

Drafting of the manuscript: SSC Chan.

Critical revision of the manuscript for important intellectual content: All authors.

All authors had full access to the data, contributed to the study, approved the final version for publication, and take responsibility for its accuracy and integrity.

\section{Conflicts of interest}

All authors have disclosed no conflicts of interest.

\section{Acknowledgement}

The authors would like to thank Miss Loreta Lee for data collection and data entry for this research.

\section{Declaration}

Portions of the results were presented in the 26th Asia and Oceania Federation of Obstetrics and Gynecology (AOFOG) Congress in the Philippines in 2019, during a talk that received the "Best Oral Presentation" award in the Urogynaecology session.

\section{Funding/support}

This research received no specific grant from any funding agency in the public, commercial, or not-for-profit sectors.

\section{Ethics approval}

Ethics approval was obtained from The Joint Chinese University of Hong Kong-New Territories East Cluster Clinical Research Ethics Committee (Ref: CREC 2015.125). The requirement for written informed consent was waived by the ethics board.

\section{References}

1. Chan SS, Cheung RY, Yiu AK, et al. Chinese validation of pelvic floor distress inventory and pelvic floor impact questionnaire. Int Urogynecol J 2011;22:1305-12.

2. Chan SS, Cheung RY, Yiu KW, Lee LL, Pang AW, Chung TK. Symptoms, quality of life, and factors affecting women's treatment decisions regarding pelvic organ prolapse. Int Urogynecol J 2012;23:1027-33.

3. Olsen AL, Smith VJ, Bergstrom JO, Colling JC, Clark AL. Epidemiology of surgically managed pelvic organ prolapse and urinary incontinence. Obstet Gynecol 1997;89:501-6.

4. Wu JM, Matthews CA, Conover MM, Pate V, Funk MJ. Lifetime risk of stress urinary incontinence or pelvic organ prolapse surgery. Obstet Gynecol 2014;123:1201-6.

5. Løwenstein E, Ottesen B, Gimbel H. Incidence and lifetime risk of pelvic organ prolapse surgery in Denmark from 1977 to 2009. Int Urogynecol J 2015;26:49-55.

6. Lowenstein L, FitzGerald MP, Kenton K, et al. Patientselected goals: the fourth dimension in assessment of pelvic floor disorders. Int Urogynecol J Pelvic Floor Dysfunct 2008;19:81-4.

7. Chan SS, Cheung RY, Lai BP, Lee LL, Choy KW, Chung TK. Responsiveness of the Pelvic Floor Distress Inventory and 
Pelvic Floor Impact Questionnaire in women undergoing treatment for pelvic floor disorders. Int Urogynecol J 2013;24:213-21.

8. Friedman T, Eslick GD, Dietz HP. Risk factors for prolapse recurrence: systematic review and meta-analysis. Int Urogynecol J 2018;29:13-21.

9. Maher C, Feiner B, Baessler K, Christmann-Schmid C, Haya N, Marjoribanks J. Transvaginal mesh or grafts compared with native tissue repair for vaginal prolapse. Cochrane Database Syst Rev 2016;(2):CD012079.

10. Lo TS, Pue LB, Tan YL, Wu PY. Long-term outcomes of synthetic transobturator nonabsorbable anterior mesh versus anterior colporrhaphy in symptomatic, advanced pelvic organ prolapse surgery. Int Urogynecol J 2014;25:257-64.

11. Dong S, Zhong Y, Chu L, Li H, Tong X, Wang J. Agestratified analysis of long-term outcomes of transvaginal mesh repair for treatment of pelvic organ prolapse. Int J Gynecol Obstet 2016;135:112-6.

12. Meyer I, McGwin G, Swain TA, Alvarez MD, Ellington DR, Richter HE. Synthetic graft augmentation in vaginal prolapse surgery: long-term objective and subjective outcomes. J Minim Invasive Gynecol 2016;23:614-21.

13. Bump RC, Mattiasson A, Bø K, et al. The standardization of terminology of female pelvic organ prolapse and pelvic floor dysfunction. Am J Obstet Gynecol 1996;175:10-7.

14. Maher C, Feiner B, Baessler K, Schmid C. Surgical management of pelvic organ prolapse in women. Cochrane Database Syst Rev 2013;(4):CD004014.

15. Haylen BT, Freeman RM, Swift SE, et al. An International Urogynecological Association (IUGA)/International Continence Society (ICS) joint terminology and classification of the complications related directly to the insertion of prostheses (meshes, implants, tapes) \& grafts in female pelvic floor surgery. Int Urogynecol J 2011;22:315.

16. Toozs-Hobson P, Freeman R, Barber $M$, et al. An International Urogynecological Association (IUGA)/ International Continence Society (ICS) joint report on the terminology for reporting outcomes of surgical procedures for pelvic organ prolapse. Int Urogynecol J 2012;23:527-35.

17. Wan OY, Chan SS, Cheung RY, Chung TK. Mesh-related complications from reconstructive surgery for pelvic organ prolapse in Chinese patients in Hong Kong. Hong Kong Med J 2018;24:369-77.

18. Yu CH, Chan SS, Cheung RY, Chung TK. Prevalence of levator ani muscle avulsion and effect on quality of life in women with pelvic organ prolapse. Int Urogynecol J 2018;29:729-33

19. Wong V, Shek KL, Goh J, Krause H, Martin A, Dietz HP. Cystocele recurrence after anterior colporrhaphy with and without mesh use. Eur J Obstet Gynecol Reprod Biol 2014;172:131-5.

20. Rodrigo N, Wong V, Shek KL, Martin A, Dietz HP. The use of 3-dimensional ultrasound of the pelvic floor to predict recurrence risk after pelvic reconstructive surgery. Aust N Z J Obstet Gynaecol 2014;54:206-11.

21. Cheung RY, Chan SS, Shek KL, Chung TK, Dietz HP. Pelvic organ prolapse in Caucasian and Asian women: a comparative study. Ultrasound Obstet Gynecol 2019;53:541-5.

22. Chen L, Ashton-Miller JA, Hsu Y, DeLancey JO. Interaction among apical support, levator ani impairment, and anterior vaginal wall prolapse. Obstet Gynecol 2006;108:324-32.

23. Stanford EJ, Cassidenti A, Moen MD. Traditional native tissue versus mesh-augmented pelvic organ prolapse repairs: providing an accurate interpretation of current literature. Int Urogynecol J 2012;23:19-28.

24. Warembourg S, Labaki M, de Tayrac R, Costa P, Fatton B. Reoperations for mesh-related complications after pelvic organ prolapse repair: 8-year experience at a tertiary referral center. Int Urogynecol J 2017;28:1139-51.

25. Deffieux X, de Tayrac R, Huel C, et al. Vaginal mesh erosion after transvaginal repair of cystocele using Gynemesh or Gynemesh-Soft in 138 women: a comparative study. Int Urogynecol J Pelvic Floor Dysfunct 2007;18:73-9.

26. Hüsch T, Mager R, Ober E, Bentler R, Ulm K, Haferkamp A. Quality of life in women of non-reproductive age with transvaginal mesh repair for pelvic organ prolapse: a cohort study. Int J Surg 2016;33:36-41.

27. Cheung RY, Lee JH, Lee LL, Chung TK, Chan SS. Vaginal pessary in women with symptomatic pelvic organ prolapse: a randomized controlled trial. Obstet Gynecol 2016;128:7380 